Jul 1st, 12:00 AM

\title{
Mesoscale modelling of interactions between rainfall and the land surface in West Africa
}

\author{
Martin Sogalla \\ Michael Kerschgens
}

Follow this and additional works at: https://scholarsarchive.byu.edu/iemssconference

Sogalla, Martin and Kerschgens, Michael, "Mesoscale modelling of interactions between rainfall and the land surface in West Africa" (2002). International Congress on Environmental Modelling and Software. 10.

https://scholarsarchive.byu.edu/iemssconference/2002/all/10

This Event is brought to you for free and open access by the Civil and Environmental Engineering at BYU ScholarsArchive. It has been accepted for inclusion in International Congress on Environmental Modelling and Software by an authorized administrator of BYU ScholarsArchive. For more information, please contact scholarsarchive@byu.edu, ellen_amatangelo@byu.edu. 


\title{
Mesoscale modelling of interactions between rainfall and the land surface in West Africa
}

\author{
Martin Sogalla and Michael Kerschgens \\ Institut für Geophysik und Meteorologie, Universität zu Köln, Germany (msog@meteo.uni-koeln.de)
}

\begin{abstract}
Within the joint research project IMPETUS (An integrated approach to the efficient management of scarce water resources in West Africa), the effect of interactions between the earth's surface and the atmosphere on fresh water availability is investigated for a river catchment in Benin by simulations with a non-hydrostatic mesoscale meteorological model. A combination of idealised ensemble simulations with a column version of the model and complex modelling of real precipitation events is employed to assess the sensitivity of precipitation to variations in the land surface. Idealised ensemble studies exhibit a dominant influence of initial soil water content and an enhanced dependence of precipitation on vegetation when soil water availability is reduced. For wet soils, the influence of parameters that determine the intensity of nearsurface turbulence is dominant. Complex modelling confirms that these relationships are useful to identify critical land use changes in realistic settings, but do not comprehensively account for the effect of heterogeneous land surface changes on regional precipitation. Instead, the interplay between surface properties, atmospheric dynamics and precipitation systems can generate intrinsic precipitation anomaly patterns that are incongruent with the imposed surface anomalies. Hence, assessments of land use change effects on precipitation for a specific region should be based on an integrated consideration of the interactions between surface processes, atmospheric forcing and precipitation systems.
\end{abstract}

Keywords: West African drought risk; Land use change; Surface-precipitation feedback; Mesoscale modelling

\section{INTRODUCTION}

Possible rainfall reduction by land surface changes in the vulnerable Sahel/Soudan zone in West Africa has been a research topic throughout the past three decades. The evolution of convective precipitation systems as the primary rainfall source in this zone is considered to be substantially influenced by surface-atmosphere exchanges of water and energy (e.g. Guichard et al. [1996]). Exchange processes depend on surface and soil characteristics that vary with soil and interception water, which are in turn influenced by antecedent rainfall. Through this feedback, land surface changes can affect regional precipitation. A review by Nicholson [2000] shows that current knowledge is not sufficient to evaluate effects of land surface changes on regional rainfall in the Sub-Saharan belt. In particular, it is still unclear to which extent the land surface plays an active role. While, among others, Taylor and Lebel [1998] find observational evidence for a positive feedback between soil moisture and rainfall anomalies, other studies (e.g. Taylor et al. [1997]) attribute a dominant role to the large-scale atmospheric flow. Numerous model studies that suggest a significant effect of the surface-precipitation feedback (cf. Nicholson [2000] for an overview) are either based on simplified conceptual models or on global circulation model (GCM) simulations that are too coarse for a regional interpretation.

This study contributes to an exploration of rainfall reduction risks by land surface changes in the Haute Vallée d'Ouémé (HVO) catchment in Benin, West Africa. Our activities are part of the joint research initiative IMPETUS (An integrated approach to the efficient management of scarce water resources in West Africa). As a first step towards an evaluation of tolerable regional land use changes with respect to rainfall availability in the HVO, our investigation focuses on rainfall sensitivity to land surface changes on time scales of individual precipitation episodes. Surfaceprecipitation interactions on the regional scale can 
be feasibly investigated by sensitivity studies with high-resolution mesoscale models that resolve regional land surface heterogeneity and simulate individual precipitation systems. For this purpose, the model FOOT3DK (Flow Over Orographically Structured Terrain, 3-dimensional, Köln Version) is employed. A twofold strategy of sensitivity studies with FOOT3DK is pursued. Idealised ensemble studies with a single column version of the model are compared with complex simulations of a real precipitation event. The economical consumption of computing resources by the idealised simulations enables the generation of a large, statistically meaningful ensemble. Analysis of the ensemble then yields the relevant parameters for an inductive introduction of hypothetical land use variations in the complex sensitivity studies. This strategy allows to consider the regional applicability of simplified approaches as well as to improve the understanding of the mechanisms that affect precipitation in complex, realistic settings.

\section{THE MODEL FOOT3DK}

FOOT3DK is a prognostic non hydrostatic limitedarea model that is designed for horizontal resolutions from $10 \mathrm{~km}$ to several $100 \mathrm{~m}$. Recent applications include the development of advanced convection parameterisations for the mesoscale (Sogalla and Kerschgens, [2001]) and process studies of the interaction between land surface and atmosphere (Shao et al., [2001]). FOOT3DK is based on the primitive equations, which are solved for a divergence-free flow. Terrain-following $\eta$-coordinates with highest resolution near the surface are used in the vertical (Brücher et al. [1998]). Atmospheric model physics include schemes for radiation, turbulence and moist physics. FOOT3DK is equipped with parameterisations of condensation, precipitation and convection that are designed for the mesoscale and tested for horizontal grid sizes of a few km (cf. Sogalla and Kerschgens [2001] for details). In particular, the convection scheme, which is originally based on the Tiedtke [1989] parameterisation, is enhanced for application on the mesoscale, including its extension to a hybrid version (Frank and Cohen [1987]). The latter yields optimal results by combination with a three dimensional transport scheme for precipitation and a subgrid-scale condensation scheme (Sommeria and Deardorff [1977]). The soil-vegetation-atmosphere transfer (SVAT) scheme in FOOT3DK is based on the two layer force-restore model ISBA (Interaction Soil Biosphere Atmosphere, Noilhan and Planton, [1989]). A detailed description of the SVAT scheme is given in Shao et al. [2001].

\section{IDEALISED ENSEMBLE STUDIES}

Fundamental influences of land surface parameters on convective rainfall are identified with a onedimensional column version of the model that reflects horizontally homogeneous conditions and a steady atmospheric forcing. This configuration is used to create an ensemble that represents a large number of different states of the land surface. From this ensemble, the SVAT parameters that predominantly influence model precipitation are obtained by statistical analysis.

\subsection{Ensemble configuration}

In the one-dimensional column version, the model simulates turbulent and thermodynamic surfaceatmosphere interactions while the forcing wind field has to be prescribed. Moist physics are incorporated by the optimal parameterisation combination as described in Section 2. Atmospheric forcing is identical for all ensemble members. All runs are initialised with the atmospheric sounding at Niamey on August 25 1999, 00 UTC. The corresponding situation lead to regionally varying rainfall in Benin during the following days. The vertical structure of the atmosphere is resolved by 25 layers with a model top at $18 \mathrm{~km}$. The model is integrated over seven days. Following the approach by deRidder [1998], atmospheric moisture and temperature profiles are relaxed towards the initial structure with a time constant of $50000 \mathrm{~s}$ to compensate for the absence of advective processes. Tests revealed that our results are basically independent of the specific choice of the relaxation time (not shown).

Table 1. SVAT parameter values and ranges used to establish the set of independent surface states.

\begin{tabular}{|c|c|c|c|}
\hline Parameters & low & Middle & high \\
\hline Roughness length $\mathrm{z}_{0}(\mathrm{~m})$ & \multicolumn{2}{|c|}{$0.05-0.35$} & $0.6-1.2$ \\
\hline Albedo $\alpha(\%)$ & \multicolumn{2}{|l|}{$5-15$} & $25-40$ \\
\hline $\begin{array}{l}\text { Relative vegetation } \\
\text { cover veg }(\%)\end{array}$ & $1-20$ & $35-60$ & $80-99$ \\
\hline Leaf area index $L A I(-)$ & $0.5-1.5$ & $2.5-3.5$ & $4.5-6.5$ \\
\hline $\begin{array}{l}\text { Soil type } \\
\text { (Saturation soil water } \\
\left.\text { content } W_{s}\left(\mathrm{~cm}^{3} \cdot \mathrm{cm}^{-3}\right)\right)\end{array}$ & \multicolumn{2}{|c|}{$\begin{array}{l}\text { Sand } \\
0.395\end{array}$} & $\begin{array}{l}\text { Loam } \\
0.435\end{array}$ \\
\hline $\begin{array}{l}\text { Relative initial soil } \\
\text { water content } W / W_{s}(\%)\end{array}$ & 35 & 60 & 75 \\
\hline
\end{tabular}

Synthetic soil and surface states are generated by SVAT parameter variations, which are summarised in Table 1. Surface parameters are varied randomly within the ranges indicated in Table 1. The resulting parameter combinations are not designed 
to correspond with regionally characteristic surfaces. Instead, statistical independence of each parameter as a prerequisite for an individual assessment of each parameter is granted. Saturation soil water content $W_{s}$ is chosen to represent soil characteristics for our statistical analysis, as the other soil parameters are by and large monotonically related to $W_{s}$. Initial soil water content is varied identically for the two model layers. All parameter combinations yield a set of 216 different states of the SVAT scheme. Our ensemble is generated by performing one simulation for each SVAT state.

\subsection{Sensitivity of precipitation to SVAT parameters}

The different states of the surface induce considerable variability in accumulated precipitation. After 72 hours, rainfall sums vary between $0 \mathrm{~mm}$ and $32 \mathrm{~mm}$. By the end of the seventh day, the spread of the ensemble increases to a range between $0 \mathrm{~mm}$ and more than $70 \mathrm{~mm}$. The relative importance of each SVAT parameter on rainfall variability is evaluated by a correlation analysis between our selection of SVAT parameters and accumulated precipitation after three days integration time (Table 2). Analogous results are obtained for other accumulation times between 2 and 7 days (not shown).

Table 2. Correlation $r$ of accumulated rainfall after 72 hours $R R_{72 h}$ with SVAT parameters. Significant values on the $95 \%$ (99\%) level according to a Gaussian error test are underlined (bold).

\begin{tabular}{|l|c|c|c|c|c|c|}
\hline Parameter $\Phi$ & $\mathrm{z} 0$ & $\alpha$ & veg & $L A I$ & $W_{s}$ & $\begin{array}{c}\text { Init. } \\
W / W_{s}\end{array}$ \\
\hline$r\left(R R_{72 h}, \Phi\right)$ & $\underline{0.15}$ & $\underline{\mathbf{0 . 3 1}}$ & $\underline{\mathbf{0 . 2 4}}$ & 0.09 & 0.05 & $\underline{\mathbf{0 . 6 7}}$ \\
\hline
\end{tabular}

Model precipitation reacts most sensitively to initial soil water content. This is not astonishing, as in the model parameterisations (cf. Shao et al, [2001]) soil water content strongly determines surface evaporation. Accumulated evaporation itself is highly correlated with precipitation by a coefficient of around 0.96 for days 2 to 7 . Surface parameters albedo and vegetation cover explain a smaller yet considerable fraction of precipitation variability. Roughness length plays a minor role while leaf area index and saturation soil water do not exhibit a significant influence.

Further insight into the mechanisms that potentially control land surface influence on rainfall is gained by stratifying the ensemble according to initial soil water content and repeating the correlation analysis for the sub-ensembles (Figure 1).

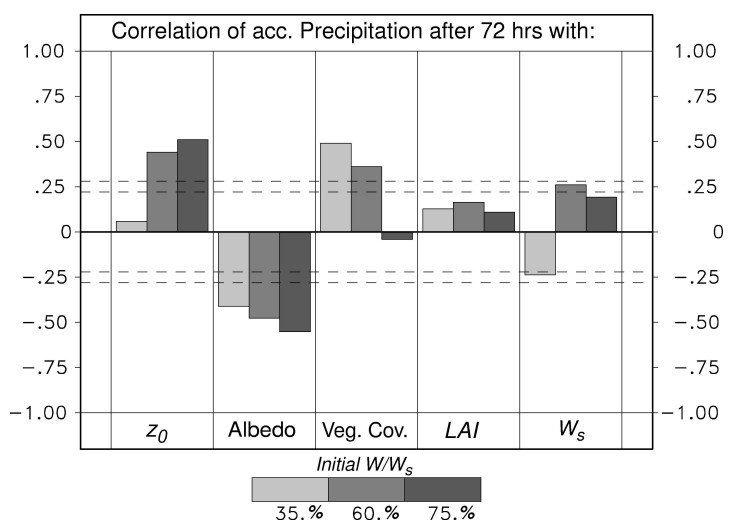

Figure 1. Correlation of accumulated precipitation after 72 hours with SVAT parameters for subensembles with equal initial soil water content. Dashed lines: $95 \%$ and 99\% significance levels.

Influence of vegetation cover is highly important for initially dryer soils, while vegetation becomes irrelevant when the soil is wet enough to evaporate at potential rates. In the latter case, variations in evaporation are dominated by changes in the intensity of turbulent motions. Hence, the influence of roughness length increases for wetter soils. The same effect is evident in albedo. However, albedo maintains a significant influence for drier soils by confining the radiative energy gain of the surface and thus its capacity to destabilise the atmosphere. Leaf area index and saturation soil water exhibit only weak and unsystematic influences.

In summary, soil water content, vegetation cover and albedo can be qualified as the most critical surface properties with respect to rainfall within the highly simplified framework applied. It will be discussed in the next section to which extent these results can be applied to complex simulations of a real precipitation event.

\section{SENSITIVITY STUDY OF A REAL PRECIPITATION EVENT}

Sensitivity studies are extended to complex realistic settings by simulations of a precipitation episode in July 28-29, 2000 in the HVO. According to satellite observations and surface rain measurements for this episode, disturbances that travel with a south-westerly near-ground flow from the monsoon region in the Guinea Zone to the northern parts of Benin repeatedly cause intense precipitation in the HVO. The sensitivity of model rain in this situation is examined by a comparison of a control simulation with sensitivity tests that are based on hypothetical land use changes. 


\subsection{Experimental set-up}

All simulations are started on 2000-07-28 00 UTC and integrated until 2000-07-30 06 UTC. FOOT3DK is operated with $9 \mathrm{~km}$ horizontal resolution, 23 vertical layers and a model top at $19 \mathrm{~km}$ height. Moist physics are represented by the optimal combination of parameterisations described in Section 2. Larger-scale forcing is accomplished by passive nesting of FOOT3DK into the Lokal-Modell (LM), (Doms and Schättler [1999]), which is the current operational mesoscale model of the German Weather Service. The LMsimulations we employ are performed at the Meteorological Institute, University Bonn, as part of activities in IMPETUS.

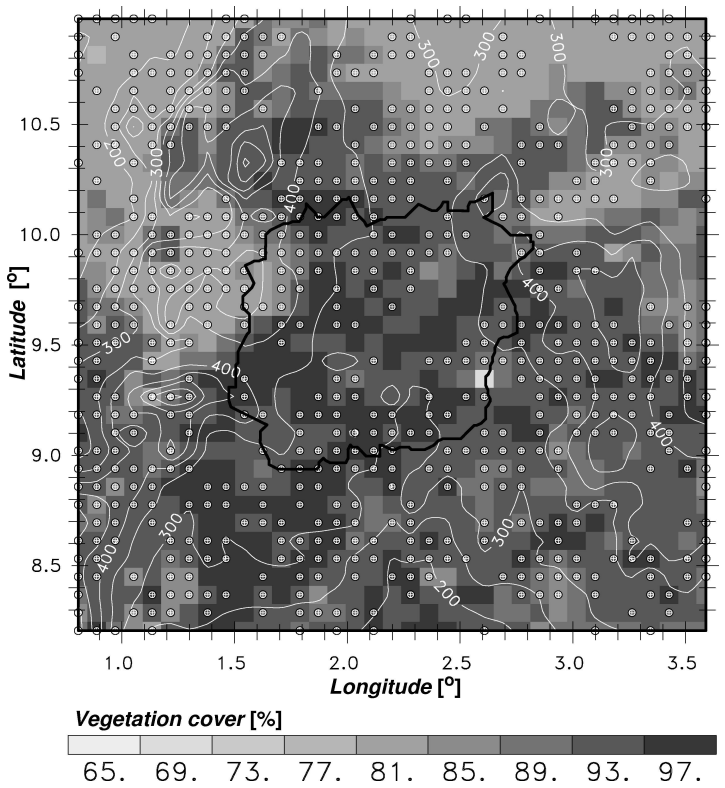

Figure 2: Simulation domain with vegetation cover, orography $(\mathrm{m}$, contour interval $50 \mathrm{~m})$ and location of the HVO catchment. Grid points with altered SVAT quantities in the sensitivity runs are marked by white dots.

The quality of presently available surface, soil and initial hydrologic data for this region is rather limited, as existing data sets are not adapted for an optimal regional representation. Surface description is based on the USGS EROS data sets "Global 30 Arc-Second Elevation Data Set" (GTOPO30, orography) and "Global Land Cover Characterization" (GLCC, land use). Soil types and initial soil water stem from LM data. Figure 2 depicts vegetation cover and orography in the model area. The simulation domain covers a square of $270 \mathrm{~km}$ side length. The HVO catchment is located in the centre of the domain. Effects of land surface variations on precipitation are investigated by introducing heterogeneous surface disturbances that, according to the results of our ensemble study, potentially act adversely on rainfall. Manipulations are performed at about $50 \%$ of the grid points within the simulation domain. Separate simulations are performed for anomalies in surface parameters, initial soil water and a combination of both. Parameter variations and simulation nomenclature are given in Table 3.

Table 3. Simulation names and parameter variations at the grid points depicted in Figure 2.

\begin{tabular}{|l|c|c|c|c|}
\hline \multirow{2}{*}{ Simulation } & \multicolumn{4}{|c|}{ Variation of Parameters: } \\
\cline { 2 - 5 } & $\mathrm{z} 0$ & $\alpha$ & Veg & Init. W/W \\
\hline CTRL & $0 \%$ & $0 \%$ & $0 \%$ & $0 \%$ \\
\hline SFC & $-50 \%$ & $+15 \%$ & $-50 \%$ & $0 \%$ \\
\hline INIT & $0 \%$ & $0 \%$ & $0 \%$ & $-66 \%$ \\
\hline SFINIT & $-50 \%$ & $+15 \%$ & $-50 \%$ & $-66 \%$ \\
\hline
\end{tabular}

\subsection{Response of precipitation to surface anomalies}

The most prominent feature in the accumulated precipitation field of run CTRL (Figure 3 ) consists of a strong precipitation band that extends diagonally from south west to north east through the simulation domain. Analysis of the temporal development in model rainfall and related flow patterns (not shown) reveals that this band owes its existence to organised convection along an extended quasi-stationary low-level convergence zone. The latter develops during daytime hours on both July 28 and 29. It is evident in the corresponding time average of near-surface winds (Figure 3 ).

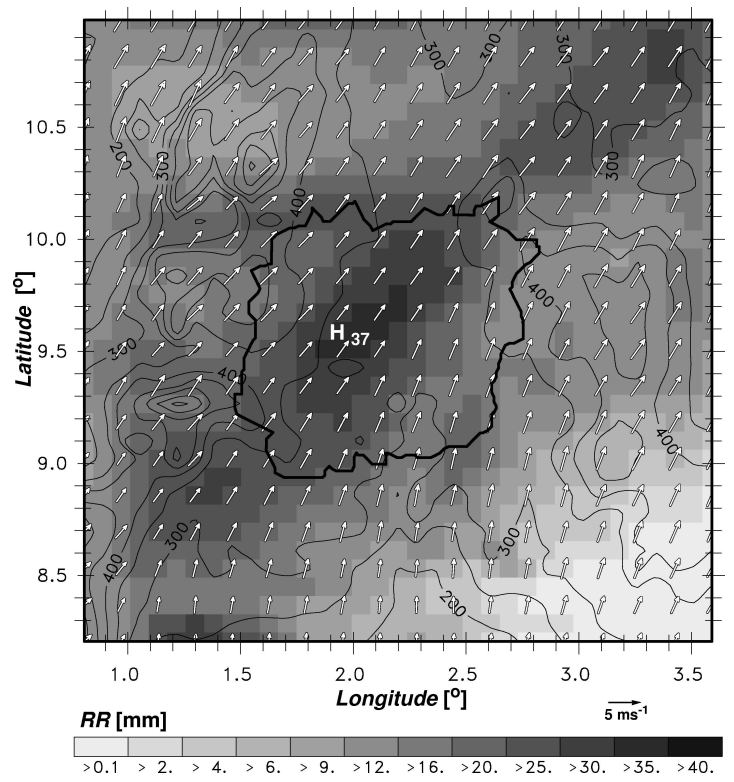

Figure 3. Accumulated precipitation and temporally averaged near-surface wind from July 28, 06 UTC to July 30, 06 UTC in CTRL. 
Simulated precipitation along this structure is predominantly generated by the convection scheme. Currently available observations are not sufficient for a comprehensive model validation (cf. Section 5). Notwithstanding the serious difficulties that limit the comparability of model precipitation fields with ground-based point measurements, a tentative comparison with the ground-based rain observation network in the area (not shown) suggests that the band of pronounced rainfall is also evident in observed precipitation.

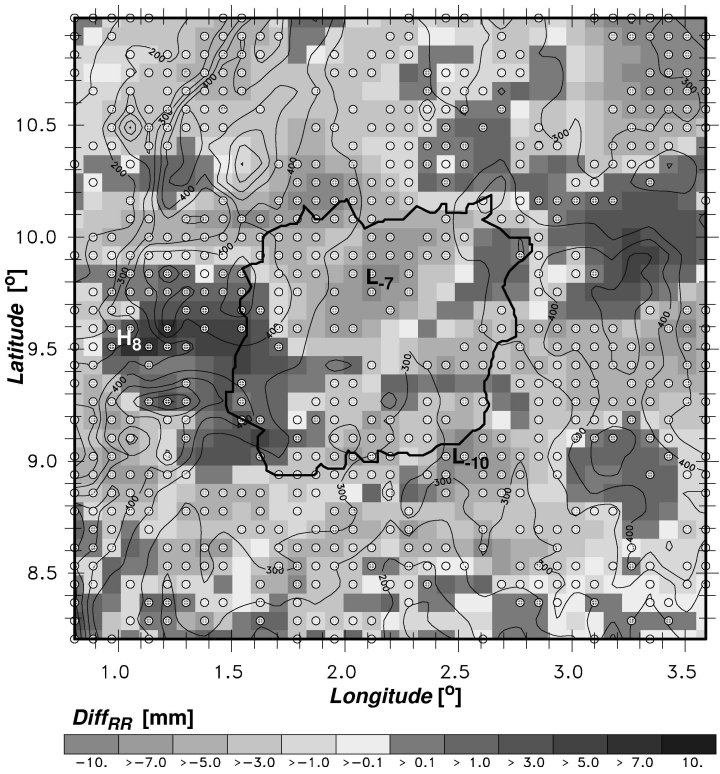

Figure 4. Precipitation difference SFINIT-CTRL accumulated from July 28, 06 UTC to July 30, 06

UTC. Grid points where surface anomalies are imposed are marked by white dots.

Effects of surface anomalies on precipitation are most pronounced in SFINIT. Discussion will be restricted to this simulation, while conclusions from our analysis qualitatively apply to SFC and INIT as well. Differences in accumulated precipitation between SFINIT and CTRL are shown in Figure 4. The imposed changes induce a rainfall reduction for $68 \%$ of the simulation domain. On average, reduction is modest, with $1.3 \mathrm{~mm}$ decrease compared to $17.2 \mathrm{~mm}$ average rainfall in CTRL. For some regions, however, rainfall is considerably reduced with decreases up to $10 \mathrm{~mm}$. In other parts, precipitation increases by values up to $8 \mathrm{~mm}$. The latter regions are mainly orographically structured while they are not confined to areas with undisturbed surface.

The generation of positive rainfall anomalies is consistent with interactions between land surface, convection, and atmospheric flow. On July 28 (not shown), convection along the main convergence zone (Figure 3) is weakened over areas where surface anomalies are imposed in accordance with inferences from our idealised study (Section 3). Associated vertical circulation patterns, that tend to stabilise the atmosphere in the vicinity of the convection line by subsidence, are correspondingly reduced. Hence, convection cells in some distance to the main convergence zone have better chances to develop in SFINIT than in CTRL. Through this interplay, a pattern of both positive and negative rainfall anomalies develops by the afternoon of July 28.

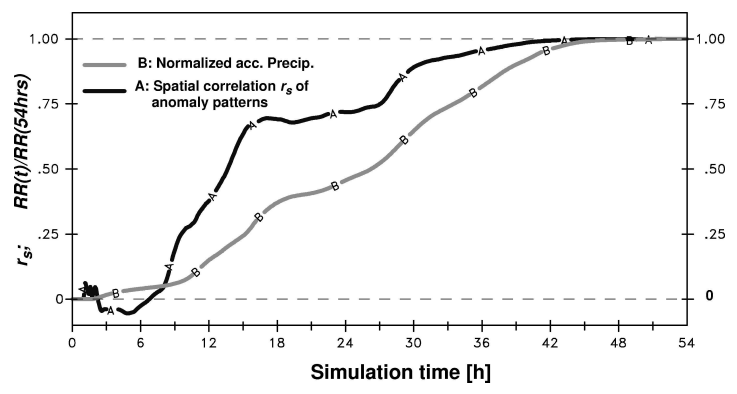

Figure 5. Spatial correlation of precipitation anomaly fields at a given time with the anomaly pattern at the end of the simulation (black curve A) and spatially averaged accumulated rainfall in CTRL normalised to its final value (grey curve B).

Once the pattern is established, it stays remarkably persistent. The temporal development of spatial correlation between anomaly patterns at a given time with the final rainfall anomaly field (Figure 5) indicates that the fundamental structure of the final anomaly field (Figure 4) is already established during the first 16 hours of the simulation. More than $60 \%$ of rain is still to fall in the subsequent 38 hours. Within the latter time interval, precipitation anomalies still grow in amplitude while basically maintaining their structure (not shown). This persistence supports the hypothesis of a positive surface-precipitation feedback.

\section{CONCLUSIONS}

The results of our study support the relevance of surface-precipitation feedback for regional rainfall on the time scale of a single precipitation episode in the HVO area in Benin. The analysis of highly simplified ensemble studies proves to be a viable tool to identify land surface properties that critically influence rainfall, i.e. soil water content, vegetation cover and albedo. The complex case study of a real precipitation event corroborates the substantial influence of land use variations on rainfall in terms of these parameters. The resulting regional structure of precipitation anomalies cannot exclusively be attributed to the surface anomaly 
pattern. The interplay of convection cells, land surface processes and larger-scale atmospheric dynamics as a whole is, however, consistent with the resulting rainfall anomalies.

It still has to be established to which degree this interaction is influenced by the specific choice of model parameterisations, in particular of the convection scheme, which predominantly accounts for rainfall in the simulations presented. Additional sensitivity tests and validation with improved observational data are thus necessary before more general conclusions can be drawn from our results. An intensive observation campaign will be carried out for the rain season 2002 to obtain feasible validation data. Likewise, the database for land surface characterisation and hydrological initialisation is to be improved in order to augment regional appropriateness and reliability of model simulations in the HVO. The corresponding data sets in need are in the process of being enhanced by joint efforts of several working groups within the framework of IMPETUS.

It is an open question whether regional rainfall anomalies induced from individual events tend to cancel out or to intensify on the time scale of an entire rain season. An answer will be sought by incorporation of our sensitivity analysis into a statistical-dynamical approach based on a classification of characteristic regimes that account for the rainfall in the HVO. Together with this classification, sensitivity tests for each regime will form the basis for a regional assessment of rainfall reduction risks by future land use changes.

\section{ACKNOWLEDGEMENTS}

This work was supported by the Federal German Ministry of Education and Research (BMBF) under grant No. 07 GWK 02 and by the Ministry of Education, Science and Research (MSWF) of the federal state of Northrine-Westphalia under grant No. 514-21200200. The authors are in particular grateful to Dr. Kai Born (University of Bonn) for providing us with the Lokal-Modell simulation data. We thank the Institute de Recherche pour le Dévéloppement, France and the Direction de la Météorologie Nationale, Benin for providing the precipitation station data.

\section{REFERENCES}

Brücher, W., Kerschgens, M.J., Martens, R., Thielen, H., Maßmeyer, K.,: Tracer experiments in the Freiburg-Schauinsland area Comparison with flow and dispersion models. Meteorologische Zeitschrift, 7, 36-40, 1998.
Doms, G., Schättler, U.: The nonhydrostatic limited-area model LM (Lokal-Modell) of DWD. Part I: Scientific documentation. Deutscher Wetterdienst, Geschäftsbereich Forschung und Entwicklung. Offenbach, Germany, 1999.

Frank, W. M, Cohen, C.: Simulation of tropical convective systems. Part I: A cumulus parameterization. Journal of the Atmospheric Sciences , 44, 3787-3799, 1987.

Guichard, F., Redelsperger, J.L.; Lafore, J.P.: The behaviour of a cloud ensemble in response to external forcings. Quarterly Journal of the Royal Meteorological Society, 122, 10431073, 1996.

Nicholson, S.E.: Land surface processes and Sahel climate. Reviews of Geophysics, 38, 117-199, 2000.

Noilhan, J.; Planton, S.: A simple parameterization of land surface processes for meteorological models. Monthly Weather Review, 117, 536549, 1989.

de Ridder, K.: The impact of vegetation cover on sahelian drought persistence. Boundary Layer Meteorology., 88, 307-321, 1998.

Shao, Y,; Sogalla, M., Kerschgens, M.; Brücher, W.: Effects of land surface heterogeneity upon surface fluxes and turbulent conditions. Meteorology and Atmospheric Physics, 78, 157-181, 2001.

Sogalla, M., Kerschgens, M.J: Berechnung lokaler Niederschlagsfelder zur Parameterisierung der nassen Deposition auf der Basis größerskaliger Vorhersagemodelle. Mitteilungen aus dem Institut für Geophysik und Meteorologie der Universität zu Köln, Heft 144., 2001.

Sommeria, G.; Deardorff, J.W.: Subgrid-scale condensation in models of nonprecipitating clouds. Journal of the Atmospheric Sciences, 34, 344-358, 1977.

Taylor C. M., R. J. Harding, A. J. Thorpe and P. Bessemoulin: A mesoscale simulation of land surface heterogeneity from HAPEX-Sahel. Journal of Hydrology, 188-189, 1040-1066, 1997.

Taylor, C.M., Lebel, T.: Observational evidence of persistent convective-scale rainfall patterns. Monthly Weather Review, 126, 1597-1607, 1998.

Tiedtke, M: A comprehensive mass flux scheme for cumulus parameterization in large-scale models. Monthly Weather Review, 117, 17791800, 1989. 